\title{
Corrigendum: Change, change, change
}

\author{
Author: Kevin Fox
}

Author: Editor-in-chief (interim)

Address for correspondence: FHJ editorial office, Royal College of Physicians, Regent's Park, London NW1 4LE.

Email: FHJ@rcplondon.ac.uk

Future Healthcare Journal 2019;6:85

The interim editor-in-chief apologises unreservedly for neglecting to mention in his editorial the contribution to the issue made by Dr Na'eem Ahmed. Dr Ahmed was in fact guest co-editor with Prof Tom Downes of the special issue, and should have been credited as such. The editorial has been updated to accurately reflect Dr Ahmed's significant contribution.

\section{Corrigendum: Staring into the crystal ball}

\author{
Author: Tom Downes
}

Author: Deputy editor-in-chief

Address for correspondence: FHJ editorial office, Royal College of Physicians, Regent's Park, London NW1 4LE. Email: FHJ@rcplondon.ac.uk

Future Healthcare Journal 2019;6:90

This editorial neglected to acknowledge the significant contribution to this issue made by editorial board member $\mathrm{Dr} \mathrm{Na}$ 'eem Ahmed, as guest co-editor of the themed content. The RCP offers sincere apologies for this oversight. We are scrutinising our processes, and have put measures in place to prevent similar errors from reoccurring in future.

The original editorial has been has been updated to acknowledge Dr Ahmed's substantial contribution to the commissioning of the themed content of the issue. 